$\underline{\underline{p}=-5}$

\title{
Exrtaction of sericin from degumming process of silk fibres and its application on nonwoven fabrics
}

\author{
Reyhaneh Fatahian $^{1 *}$, Mehdi Noori ${ }^{2}$, Ramin Khajavi ${ }^{3}$ \\ ${ }^{1}$ Faculty of textile, Islamic azad university of Yazd, Yazd, Iran \\ ${ }^{2}$ Faculty of textile, University of Guilan, Guilan, Iran \\ ${ }^{3}$ Faculty of textile, Islamic azad university of south Tehran, Tehran, Iran \\ *Corresponding author E-mail: reyhaneh.fatahyan@gmail.com
}

\begin{abstract}
Silk sericin is a family of water-soluble proteins extracted from the silkworm cocoon. Studies have been attempted to recycle the sericin waste sericulture to develop value-added products in biomedical, pharmaceutical, cosmetic and food industries. Thus, increased production of sericin-containing wastewater from sericulture is predicted soon. In this study, some of the separation methods of sericin from silk waste water solution also extracted sericin characteristics have been investigated by FTIR. This study has determined antibacterial action of sericin in E. coli and Micrococcus luteus samples and illustrated sericin capacity as an antibacterial factor by confirming sericin on bacterial growth. Results of this study indicated discretion possibility of sericin from silk wastewater. Extracted sericin value depends on temperature and time. Characteristics of nonwoven textile coated by sericin had represented increasing of tensile and bending length and also showed that sericin with high concentration had preventive capacity of Micrococcus luteus bacterial on nonwoven textile.
\end{abstract}

Keywords: Silk; Sericin; Degumming; Nonwoven.

\section{Introduction}

Silk which is extracted from silkworm is a natural protein and is obtained from distillation and the polymerization of different harmonic alpha amino acids with long chains. Silk fibers consist of $97 \%$ protein and the rest of waxes, carbohydrates, pigments and mineral composition that protein in silk fibers is $0.75 \%$ fibroin and $0.25 \%$ sericin (Kongkachuichay et al. 2002). In terms of strength and firmness, natural silk has more strength. There are only a limited number of synthetic fibers that are stronger than natural silk. Sericin is second type of silk proteins that contains 18 amino acids such as original amino acids and is specified by the presence of $32 \%$ serine. The total amount of hydroxy acids in sericin is $0.45 \%$. $3 / 42 \%$ is polar amino acid and $12.2 \%$ of the rests of non-polar are amino acids. Their main role is surrounding and covering fibroin (Padamwar et al. 2004). Sericin is a water-soluble protein. Sericin dissolves in polar solvents or hydrolyzes in acidic solutions or in alkalis acids or decomposed with protease. Size of the sericin molecules depends on factors such as temperature, $\mathrm{PH}$ and process time (Zhang et al. 2002). Sericin silk (SS) can be extracted by various methods, which led to present various physical and biological properties in the sericin. Sericin that produced by various methods of extraction have different molecular weights, zeta power, particle size and content of amino acids is different. The difference in the amount of amino acids from different ways to extract sericin on its cell growth and secretion of collagen affects in cells (Aramwit et al. 2010). Sericin because of the properties such as resistance to oxidation, anti-bacterial, resistance to UV radiation, anti-wrinkle, wound healing and humidity absorption, easy to humidity absorption and distribution is remarkable and is widely used in pharmaceutical industry and medical, cosmetic, food and polymer, biomaterials, fiber and textiles. Sericin protein can be combined with other molecular substances, especially synthetic polymers as cross linking, copolymerization and mixing in order to produce materials with improved properties. This protein can be used as an improved reactor or a coating material for natural and synthetic fibers, textiles and polymer goods (Zhang et al. 2002). (Saravart et al. 2003) Provided sericin solution for coating nylon and polyester in order to use as an anti-oxidant and anti-microbial to increase air filters properties. Furthermore, (Gulrajani et al. 2008) investigated sericin, which is connected to ethylene glycol diglycidyl ether that grafted on polyester fabric with $\mathrm{N}$-vinylamide form and hydrolyzed with sulfuric acid. Moisture absorption from the properties of completed textiles were improved, and antistatic properties were showed under its original fabric without changes. In this paper, for degumming silk two separate methods were used. Then sericin separation was done from degumming process and extracted sericin properties were examined on the nonwoven layer Also, extracted sericin was described as an antibacterial factor on the growth of bacteria.

\section{Experimental setup}

\subsection{Material}

Silk cocoons which are used from available silk cocoons in Iran, known as hybrid cocoon that comes from mixing Japanese and Chinese's butterfly were prepared. Layer nonwoven fabric used throughout the study that is made by polypropylene and provided 
by thermo-bonding method. Laboratory-grade materials such as ammonium sulfate and sodium carbonate were used.

\subsection{Sericin degumming from silk}

\subsubsection{Degumming in distilled water}

For extracting sericin, the cocoon is divided into small pieces and in distilled water bath with $\mathrm{L}: \mathrm{R} 1: 30$, in the period of $30,60,90$ and 120 minutes and is heated in boiling temperature, $80^{\circ} \mathrm{C}$ and $60^{\circ} \mathrm{C}$.

\subsubsection{Degumming in the presence of sodium carbonate}

The cocoon is divided into small pieces and in distilled water bath with L: R 1:30, in the period of 30, 60, 90 and 120 minutes and is heated in boiling temperature, $80^{\circ} \mathrm{C}$ and $60^{\circ} \mathrm{C}$ in the presence of sodium carbonate.

\subsection{Sedimentation method}

For the formation of deposition to be obtained degumming soluble in any processes by added $40 \mathrm{~g}$ of ammonium sulfate for each 100 $\mathrm{ml}$ solution and the resulting sedimentation is filtered and dried to powder sericin at ambient temperature.

\subsection{Determine the weight of the sediment}

After removal of the sediment, it dried at ambient temperature, and its weight was measured. According to the amount of initial weight reductions of degumming silk, it can be calculated the amount of sericin sedimentation.

\subsection{Dialysis of sericin solution}

The resultant sediment was dissolved in distilled water and put under dialysis. For this purpose, the dialysis bag is used. For purification of sericin mostly need to separate ions and molecules in the solution or be exchanged with ions and other molecules to reduce or change their density which is usually done by dialysis. For this purpose, sericin solution is poured into a membranous sac and placed it in distilled water. Additional molecules and ions in the solution through a membrane bag slowly exits as well as ions present in the environment can also penetrate into the solution bag and it will be make thinner and exchange the ion. At this point the bag containing solution are placed in distilled water for 24 hours and at this time, distilled water is inside the bag is replaced every few hours. After this time and until the sericin solution reach to steady state, the dialysis solution is placed inside the refrigerator. (The dialysis done for both methods of degumming with distilled water and in the presence of sodium carbonate).

\subsection{Cover nonwoven layer with sericin}

Crop the layers to the same size. Sericin nonwoven layers impregnated in the solutions which obtained from the resin and after a minute they brought out of solution and dried at ambient temperature.

\subsection{FTIR Analysis}

Sediment obtained in dialysis step, for analysis by FTIR device turns to pills to solve kbr field device and then the related graphs extracted from this device is considered.

\subsection{Determine the strength coated with a layer sericin.}

Layer which is covered with a sericin, placed under the operational strength tests with firmness tester machine, which means the layers in dimensions of $5 \times 25 \mathrm{~cm}$ longitudinally cut and then put them on the distance between the upper and lower jaws is $20 \mathrm{~cm}$, and their longitudinal strength is calculated.

\subsection{Measure the length of bending layer covered with sericin}

To measure the bending length of layer, which is covered with sericin, the bending test machine is used. Device angle is $41 / 5^{\circ}$. The layer is cut to $2 \times 25 \mathrm{~cm}$ and placed it on the flat surface of device. Then slowly move forward until the layer bends and hit the ramp device. Then, using a ruler to measure the bending length.

\subsection{Microbial testing}

For microbial testing, Escherichia Coli and Micrococcus luteus, bacteria were used and this process is done in two stages: 1- Silk cocoon divided into small pieces and in distilled water with $\mathrm{L}: \mathrm{R}=$ 1:30 put it in a glass and close its lid and in an autoclave at a temperature of $120^{\circ} \mathrm{C}$ and placed for one hour. After passing the time, the pre-sterilized layer to sericin solution was impregnated for a minute and at temperature of $60^{\circ} \mathrm{C}$ it was dried for 15 minutes and layer with a diameter of $6 \mathrm{~mm}$ was cut. 2- The second method is similar to first method and only the degumming method was done in the presence of sodium carbonate. One loop of bacterial colonies from a nutrient agar (NA) slant was grown for $18 \mathrm{~h}$ in $20 \mathrm{~mL}$ of nutrient broth $(\mathrm{NB})$ at $37^{\circ} \mathrm{C}$ by shaking at $160 \mathrm{rpm}$. The cell suspension was diluted with fresh NB to a final density of $1.5 \times 10^{8}$ colony forming units $(\mathrm{CFU}) / \mathrm{mL}$ corresponding to a McFarland value of 0.5 . Assay plates were prepared by pouring with warm melted NA medium $(20 \mathrm{~mL})$ containing the bacterial suspension $(200 \mu \mathrm{L} ; 3 \times 107 \mathrm{CFU})$. Sterile filter discs $6 \mathrm{~mm}$ in diameter was impregnated with 20,30 , and $40 \mu \mathrm{g}$ of eri sericin solution and placed on the inoculated agar surface. At the end of the incubation period $(20 \mathrm{~h})$, antimicrobial activity was determined by the clear zones around the filter discs.

\section{Results and discussion}

\subsection{Infrared analysis of sericin powder}

Fig. 1 and 2 are FTIR spectrum for two samples extracted by boiling the cocoons sericin in distilled water for 90 minutes as well as cocoons in boiling distilled water in the presence of sodium carbonate for 90 minutes which has been under dialysis. About (1cm) 3410-3460, first peak appears which is related to $\mathrm{H}-\mathrm{N}$ amino. Then one peak at around 2923 can be seen that related to $\mathrm{H}-\mathrm{C}$ alkane and then on around 2857-9 a twin peak can be seen that related to $\mathrm{H}-\mathrm{C}$ of alkane. And then in around 1551-1560 which is indicated the presence of $\mathrm{H}-\mathrm{N}, \mathrm{O}=\mathrm{C}$ and also $\mathrm{C}=\mathrm{C}$. And then the 1419-1401 peak is observed that is related to $\mathrm{H}-\mathrm{C}$ alkane. Generally, the links of amino acids in these spectra are observed.

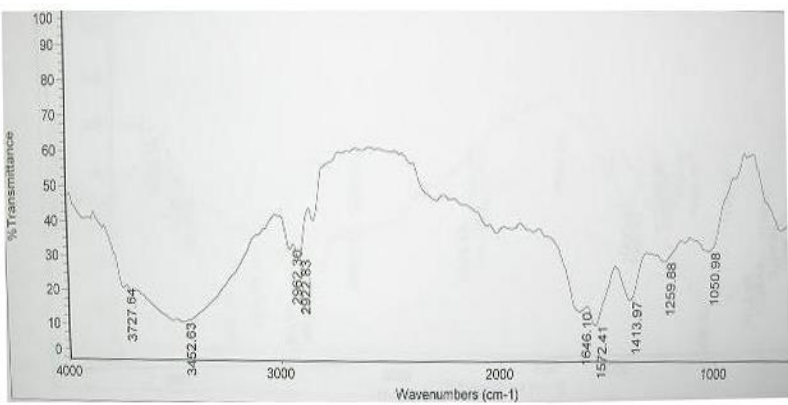

Fig. 1: Spectrum of FTIR Test for Extracted Sample in Distilled Water. 


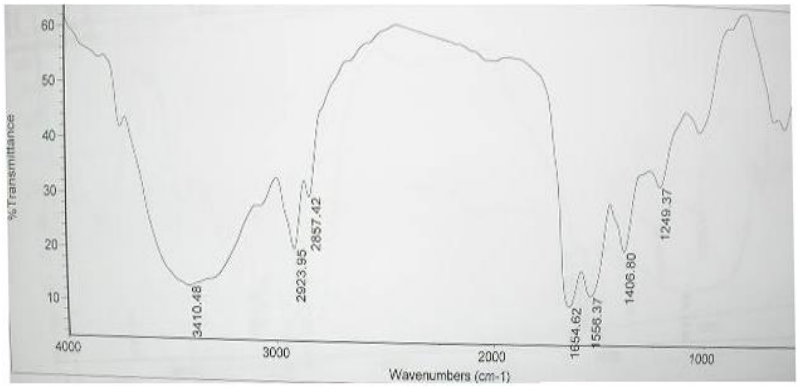

Fig. 2: Spectrum of FTIR Test for Extracted Sample in the Presence of Sodium Carbonate.

\subsection{Longitudinal strength changes over time}

After examining the longitudinal strength layers impregnated with extracted sericin solution from degumming method in distilled water, it was found that at boiling point with increasing time, the longitudinal strength increased until 90 minutes and then decreased from 90 to 120 minutes. At $80^{\circ} \mathrm{C}$ from 30 to 60 minutes, longitudinal strength increased with increasing time and then it is almost at the same level and stable. It is almost stable at $60^{\circ} \mathrm{C}$ from 30 minutes to 60 minutes and increased from 60 minutes to 90 minutes and from 90 minutes to 120 minutes is almost at the same level. Comparing the three temperatures, it can be concluded that most longitudinal strength of the sample dipped in boiling point is at the time of 90 minutes and also longitudinal strength increases with increasing temperature and it only reversed at the time of 120 minutes. (Fig. 3)

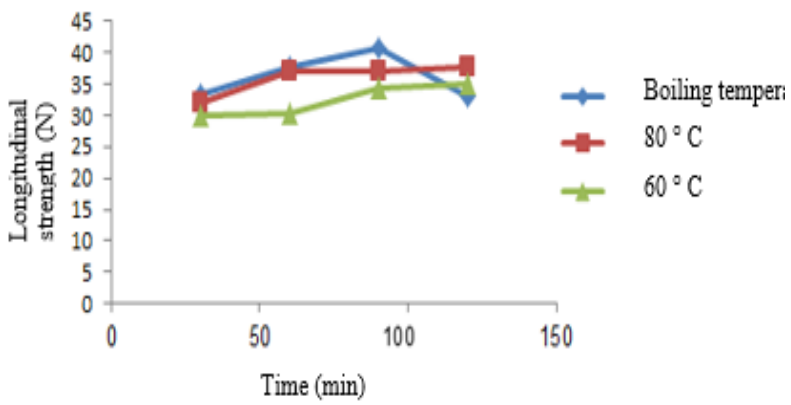

Fig. 3: Longitudinal Strength into the Boiling Temperature of $60^{\circ} \mathrm{C}, 80^{\circ}$ $\mathrm{C}$ without the Presence of Sodium Carbonate.

Also, the results showed that the impregnated layers from extracted sericin in presence of sodium carbonate in boiling temperature with increasing time from 30 minutes to 60 minutes, increased longitudinal strength and after that decreased from 60 minutes to 90 minutes and from 90 minutes to 120 minutes have a slightly increasing and remained almost at the same level. At $80^{\circ} \mathrm{C}$ with increasing time, longitudinal strength has a slightly increasing and has no significant changes. Also at $60^{\circ} \mathrm{C}$ with increasing time, longitudinal strength has a slightly increasing and also concludes that with increasing temperature, longitudinal strength was increased and this is the maximum value for the sample impregnated at boiling temperature and the time of 60 minutes. (Fig. 4)

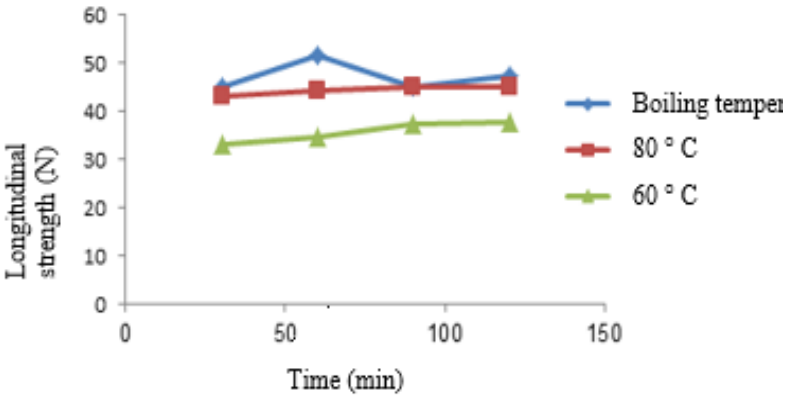

Fig. 4: Longitudinal Strength into the Boiling Temperature of $60^{\circ} \mathrm{C}, 80^{\circ}$ $\mathrm{C}$ with the Presence of Sodium Carbonate.

\subsection{Bending length changes over time}

After considering the figures of bending lengths with a solution of sericin from degumming methods of distilled water, it was observed that at the boiling temperature the rate of bending length increased with increasing time to 90 minutes and after that from 90 minutes to 120 minutes reduced dramatically. At $80^{\circ} \mathrm{C}$ with increasing time, the rate of bending length has been increased. Only at 60 minutes to 90 minutes almost remained at the same level. At $60^{\circ} \mathrm{C}$ with increasing time, the rate of bending length has been increased. Totally, it can be seen that the most rate of bending length is at boiling temperature at the time of 90 minutes. (Fig. 5)

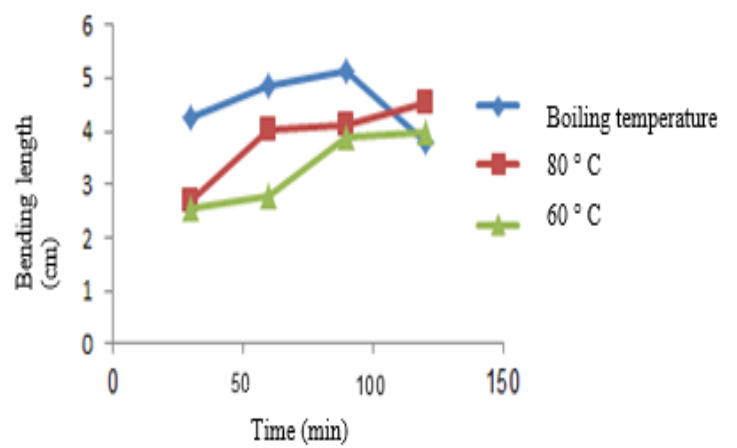

Fig. 5: Bending Length into the Boiling Temperature of $60^{\circ} \mathrm{C}, 80^{\circ} \mathrm{C}$ without the Presence of Sodium Carbonate.

Also, the results showed that the layers impregnated with a solution of sericin with the presence of sodium carbonate at boiling temperature, bending length increased from 30 minutes to 60 minutes and after that with increasing time it has been decreased. At $80^{\circ} \mathrm{C}$ the bending length increased with increasing time and at $60{ }^{\circ} \mathrm{C}$ the bending length with increasing time from 30 minutes to 90 minutes remained almost at the same level and after that it has been increased at 120 minutes. Totally, it can be seen that the most rate of bending length is at boiling temperature at the time of 60 minutes. (Fig. 6)

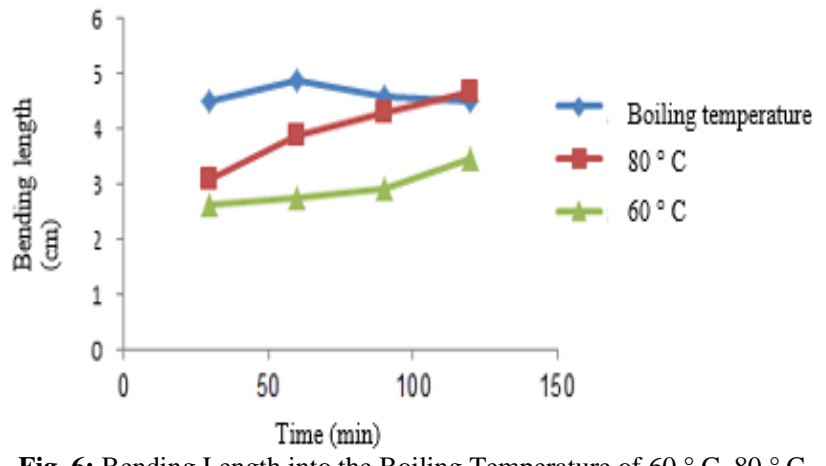

Fig. 6: Bending Length into the Boiling Temperature of $60^{\circ} \mathrm{C}, 80^{\circ} \mathrm{C}$ with the Presence of Sodium Carbonate.

\subsection{Antimicrobial test}

Test was done for Both of the Escherichia Coli and Micrococcus luteus bacteria in the NA environment in two different densities of sericin. Escherichia Coli bacterium was used at NA plate. The impregnated layers with a solution of sericin extracted from degumming method with distilled water in the presence of sodium carbonate in density of $10 \mathrm{mg} / \mathrm{mlit}$ have not reacted to the Escherichia Coli bacteria and also at NA plate that is used micrococcus luteus bacteria. Impregnated layers of both methods with density of $10 \mathrm{mg} /$ mlit have not the ability of deterrent of Micrococcus luteus bacteria and when the density was increased at NA, plate that is used micrococcus luteus, impregnated layer with sericin from degumming method in the presence of sodium carbonate was reacted to the Micrococcus luteus bacteria had the ability of deterrent of Micrococcus luteus bacteria. Totally it can be concluded 
that when the density of sericin was increased, impregnated layers can show its antibacterial properties to Micrococcus luteus bacteria but impregnated layers with sericin with more density have not affected on Escherichia Coli bacteria.

\section{Conclusion}

The results of this study showed that separation of sericin from waste of silk degumming through sedimentation of sericin by ammonium sulfate, and dialysis of sediment was possible and the quantity of separation of sediment from waste, which is depended on several factors were studied in for both temperature and time. With Investigation of longitudinal strength of impregnated layers with sericin, the results showed that with increasing temperature, longitudinal strength increased but with increasing time, bending length first increased and then with decreasing degumming, the quantity of sediment was decreased. Results of measuring the bending length showed that the bending length depends upon the percentage of degumming and quantity of sediment and if the percentage of degumming and quantity of sediment increased, the bending length will be increased. Furthermore, it was observed that with increasing temperature, the bending length was increased. However, with increasing time the bending length with increasing the quantity of sediment was increased, and it was decreased with decreasing the quantity of sediment. The results of the antimicrobial properties of sericin showed that the obtained sericin from degumming in the presence of sodium carbonate was affected on the Micrococcus luteus bacteria, and it can be obtained better antimicrobial properties with the increasing of density of sericin. Totally, it can be concluded that the separation of sericin from the sediment of degumming is possible and the quantity of separation sericin depends on temperature, time and $\mathrm{PH}$ in alkaline $\mathrm{PH}$ which means that in presence of sodium carbonate more sericin will be extracted but faster in more times and high temperatures the vulnerability of sericin will be obtained. Also, coating the nonwoven textiles with sericin caused to increase their weight, strength and bending length. According to the sericin antimicrobial properties and its impact on the nonwoven textiles, it can be used in coating nonwoven textiles because these textiles are widely used in medical sciences and health industries.

\section{References}

[1] Kongkachuichay, P., Shitangkoon, A., \& Chinwongamorn, N (2002). Thermodynamics of adsorption of laccaic acid on silk. Dyes and pigments, 53(2), 179-185. https://doi.org/10.1016/S01437208(02)00014-1.

[2] Padamwar, M. N., \& Pawar, A. P. (2004). Silk sericin and its applications: A review, journal of scientific \& industrial Research, vol. 63, pp 323-329.

[3] Zhang, Y. Q. (2002). Applications of natural silk protein sericin in biomaterials. Biotechnology advances, 20(2), 91-100. https://doi.org/10.1016/S0734-9750(02)00003-4.

[4] Aramwit, P., Kanokpanont, S., Nakpheng, T., \& Srichana, T. (2010). The effect of sericin from various extraction methods on cell viability and collagen production. International Journal of Molecular Sciences, 11(5), 2200-2211. https://doi.org/10.3390/ijms11052200.

[5] Sarovart, S., Sudatis, B., Meesilpa, P., Grady, B. P., \& Magaraphan, R. (2003). The use of sericin as an antioxidant and antimicrobial for polluted air treatment. Rev Adv Mater Sci, 5(3), 193-198.

[6] Gulrajani, M. L., Brahma, K. P., Kumar, P. S., \& Purwar, R. (2008). Application of silk sericin to polyester fabric. Journal of applied polymer science, 109(1), 314-321. https://doi.org/10.1002/app.28061. 